\title{
When it rains, it pours: detecting seasonal patterns in utilization of maternal healthcare in Mozambique using routine data
}

Briana Stone $^{1 *}$ D, Júlia Sambo ${ }^{2}$, Talata Sawadogo-Lewis ${ }^{1}$ and Timothy Roberton ${ }^{1}$

\begin{abstract}
Background: Climatic conditions and seasonal trends can affect population health, but typically, we consider the effect of climate on the epidemiology of communicable diseases. However, climate can also have an effect on access to care, particularly in remote rural areas of low- and middle-income countries. In this study, we investigate associations between the rainy season and the utilization of maternal health services in Mozambique.

Methods: We examined patterns in the number of women receiving antenatal care (ANC) and delivering at a health facility for 2012-2019, using data from Mozambique's Health Management Information Systems. We investigated the association between seasonality (rainfall) and maternal health service utilization (ANC and institutional delivery) at national and provincial level. We fit a negative binomial regression model for institutional delivery and used it to estimate the yearly reduction in institutional deliveries due to the rainy season, with other factors held constant. We used the Lives Saved Tool (LiST) to model increases in mortality due to this estimated decrease in institutional delivery associated with the rainy season.
\end{abstract}

Results: In our national analysis, the rate of ANC visits was $1 \%$ lower during the rainy season, adjusting for year and province (IRR $=0.99,95 \% \mathrm{Cl}$ : 0.96-1.03). The rate of institutional deliveries was $6 \%$ lower during the rainy season than the dry season, after adjusting for time and province (IRR $=0.94,95 \% \mathrm{Cl}: 0.92-0.96)$. In provincial analyses, all provinces except for Maputo-Cidade, Maputo-Province, Nampula, and Niassa showed a statistically significantly lower rate of institutional deliveries in the rainy season. None were statistically significantly lower for ANC. We estimate that, due to reductions in institutional delivery attributable only to the rainy season, there were 74 additional maternal deaths and 726 additional deaths of children under the age of 1 month in 2021, that would not have died if the mothers had instead delivered at a facility.

Conclusion: Fewer women deliver at a health facility during the rainy season in Mozambique than during the dry season. Barriers to receiving care during pregnancy and childbirth must be addressed using a multisectoral approach, considering the impact of geographical inequities.

Keywords: Seasonality, Mozambique, Maternal health, Health care access

\footnotetext{
* Correspondence: bstone14@jhu.edu

'Johns Hopkins Bloomberg School of Public Health, Baltimore, MD, USA

Full list of author information is available at the end of the article
}

C C The Author(s). 2020 Open Access This article is licensed under a Creative Commons Attribution 4.0 International License, which permits use, sharing, adaptation, distribution and reproduction in any medium or format, as long as you give appropriate credit to the original author(s) and the source, provide a link to the Creative Commons licence, and indicate if changes were made. The images or other third party material in this article are included in the article's Creative Commons licence, unless indicated otherwise in a credit line to the material. If material is not included in the article's Creative Commons licence and your intended use is not permitted by statutory regulation or exceeds the permitted use, you will need to obtain permission directly from the copyright holder. To view a copy of this licence, visit http://creativecommons.org/licenses/by/4.0/ The Creative Commons Public Domain Dedication waiver (http://creativecommons.org/publicdomain/zero/1.0/) applies to the data made available in this article, unless otherwise stated in a credit line to the data. 


\section{Background}

In countries with marked changes in climatic conditions depending on season, these conditions can determine epidemiologic disease patterns of "seasonal" diseases. For example, malaria or cholera incidence are expected to spike during the rainy season, due to increases in mosquito populations and stagnating waters caused by the high volume of rain [1-3]. However, seasonal pattern in disease incidence or health outcome is not limited to diseases with such a direct relationship to weatherrelated events. Indeed, existing studies have shown that fluctuations in access and utilization of health services are also linked to the ability to travel to a health facility at different times of the year [4-7].

Transportation and distance-related issues are commonly reported barriers to accessing health care services in Mozambique $[8,9]$. According to Mozambique's most recent Demographic and Health Survey (DHS 2011), the biggest problem of access to health care reported by women is the distance to health unit. For example, in Zambezia, $80 \%$ of women said distance was a problem for accessing health care [10]. In a study investigating healthcare service availability in Mozambique, an average of $40 \%$ of the population live 2 or more hours of walking distance from the closest health facility [11]. Difficulty accessing health care is exacerbated when rain floods the roads, making transportation more difficult and causing further delays [12]. A qualitative study in rural Mozambique described transportation and poor condition of roads as barriers to assessing health facilities in Zambezia, with one participant describing a full day's journey of $150 \mathrm{~km}$ to access an antiretroviral therapy clinic the next day [13]. Roads in Mozambique are mostly unpaved and vulnerable to the floods and heavy precipitation frequently experienced in Mozambique, with large sections of the few paved roads virtually impassable during the rainy season [14]. The impact of severe weather on road infrastructure resulting in long travel times and, in some cases, isolation from health facilities has also been documented [15].

Maternal deaths are a result of complications during and following pregnancy and childbirth, and most are preventable through the provision of basic health services - including ensuring that every birth occurs with the assistance of skilled health personnel [16]. In 2002, Mozambique signed up to the millennium development goals (MDGs), which included a commitment to reduce the maternal mortality ratio by three quarters between 1990 and 2015. Mozambique committed to the Sustainable Development Goals (SDGs) in 2015, which includes ensuring healthy lives and promoting well-being for all ages, and implemented the 2030 Agenda, including all 17 SDGs, into the framework of Mozambique's national development plan in 2017. Despite a 50\% reduction since 1990 [17], maternal mortality remains at a concerningly high rate (489/100,000 live births) [18] .

Mozambique's Health Sector Strategic Plan (PESS, Plano Estratégico do Sector da Saúde) for 2014-2019 included accelerating progress in the reduction of maternal and neonatal mortality as one of Mozambique's health priorities [19]. To accelerate progress of access to sexual and reproductive health programs specifically, the PESS included strategies and interventions intended to increase demand for antenatal (ANC) and institutional deliveries. These include encouraging women through community involvement to attend at least 4 ANC visits during the course of their pregnancy, constructing "maternity waiting homes" at health facilities where women can stay while waiting for labor to start, and using Traditional Birth Attendants (TBA) and community health worker participation in referral systems for pregnant women and women during or after labor [19]. It is clear that in Mozambique, the government has made a commitment to the reduction of maternal mortality and prioritized improved demand for institutional deliveries.

A limited number of studies have analyzed how the rainy season in Mozambique or neighboring countries affects access to maternal health care services $[5,15,20]$. To the best of our knowledge, no study has specifically attempted to identify seasonal patterns in the delivery of maternal health services using routine data. Because it is collected on an ongoing, uninterrupted basis, routine data is especially beneficial for identifying and analyzing trends.

In this study, we sought to quantitatively investigate the effect of the rainy season on utilization of maternal health services at a health facility. We hope that these findings will help inform decision-makers as they decide on the allocation of resources to address bottlenecks in improving maternal health outcomes in Mozambique.

\section{Methods \\ Data sources}

We obtained routine monthly count data from the national health management information system (HMIS) for at least four completed ANC visits (ANC4) and count data of women delivering at health facilities (institutional delivery) in each of the 11 provinces, including the capital, Maputo-Cidade.

Data for January 2012 to December 2015 came from Mozambique's HMIS, Modulo Basico. The HMIS transitioned to the DHIS-2-based system called Sistema de Informação para a Saúde-Monitoria e Avaliação (SISMA) in 2016, and data from January 2017 to August 2019 comes from SIS-MA. The first 5 months of 2012 were excluded to account for slow adoption of the HMIS system in Mozambique. Of note, there were delays in the implementation of the systems transition activities, and completeness of the data reported through the SIS- 
MA remains a concern [21]. We were not able to obtain data for the year of transition (2016).

Meteorological data was derived from the Climate Hazards Group InfraRed Precipitation with Stations (CHIRPS) dataset via the USAID Famine Early Warning Systems Network [22]. The publicly available CHIRPS dataset contains daily rainfall estimates from rain gauge and satellite observations for each province, excluding the capital Maputo-Cidade. Because weather station density over Mozambique is low and rainfall data collected is therefore very dependent on proxy satellite data for large areas, rainfall data was used to determine seasons.

\section{Covariates}

Precipitation data was retrieved for the study period, including monthly rainfall, which ranged from 2.40 to $538.60 \mathrm{~mm}$ from January 2012 to August 2019. A binary seasonality predictor for rainy and dry season was created based on average rainfall per month (Additional File 1). We categorized the rainy season as January, February, March, and December, the months with the highest rainfall, and all other months as being the dry season. A binary predictor variable was created for SIS-MA after 2016 versus the older HMIS, Modulo Basico, to account for any changes due to the new system. Nampula, the province with the largest population, represented the reference category for provinces.

\section{Outcome variables}

We assessed (1) frequency of ANC visits, calculated as the monthly total number of pregnant women completing 4 ANC visits at a health facility, and (2) the total number of pregnant women delivering at a health facility each month as outcome variables. We fit separate regression models for each outcome to assess whether or not being in the rainy season would decrease the frequency of maternal health service-related visits.

\section{Analysis}

We conducted statistical analyses of the association between seasonality and counts of maternal health facility visits at the national and provincial level. We first looked at the distribution of completed ANC4 visits and institutional deliveries, including the frequency of zero counts, and examined summary statistics, such as mean, median, skewness, and variance. We checked for collinearity by investigating viariance inflation factors (VIF). As VIF for both models were well below 2.00, we assumed that collinearity to be negligible for the models fitted here.

To determine the most appropriate approach for examining the association between rainy season and number of facility visits, we evaluated a number of regression models, including the Poisson model, a negative binomial mean- dispersion model, and a generalized linear model (GLM) assuming an overdispersed Poisson model.

After evaluating the predictive performance of each model for each outcome using Akaike information criterion (AIC), we found that the negative binomial model showed the best model fit to the data. We fit the overall model for each outcome (counts of ANC; counts of institutional deliveries), adjusted for time (monthly), to account for unmeasured confounders that may vary over time, HMIS change, and region (as provinces). Accounting for heterogeneity across province in both frequency of facility visits and precipitation across Mozambique, provincial associations were estimated by stratifying by provinces in our model.

We conducted all analyses using Stata version 15.1 (StataCorp, College Station, TX) [23]. Inferences of statistically significant effects were based on a-priori defined significance level of alpha $=0.05$ or if the $95 \%$ confidence interval overlapped the null value of incident rate ratio $(\mathrm{IRR})=1.00$.

We then calculated the predicted number of institutional deliveries after 2012 using the fitted negative binomial model, under two scenarios: first, with months in their original rainy/dry season categorization; and second, with all months considered to be in the dry season. We summed the predicted counts for each scenario and took the difference as an estimate of how many women would not deliver at a facility because of the rain. We used the Lives Saved Tool (LiST) to model the increase in mortality due to this predicted decrease in utilization of institutional delivery associated with the rainy season. LiST is a mathematical modeling tool which allows users to model the impact of scaling up maternal, newborn, child health and nutrition (MNCH\&N) interventions on mortality and nutritional outcomes [24]. Our predicted reduction in service utilization of institutional delivery corresponded to a $2 \%$ decrease. We therefore created a projection in LiST keeping utilization in 2020 at $64.8 \%$ and dropped it to $63.5 \%$ for 2021 . We used 2020 for our base year and 2021 for our target year.

\section{Results}

\section{Descriptive statistics}

There was on average 515,622 women per month who completed ANC4 visits in the rainy season compared to 590,234 in the dry season. For institutional deliveries, the average for rainy season was 421,643 and 478,143 for dry season. Descriptive statistics are presented in Table 1.

Figure 1 shows the number of women completing four ANC visits each month and monthly deliveries at a health facility averaged per month over this time period nationally. Both of these indicate a decrease in frequency in the months with heavier rainfall (Fig. 1). Additional files show the monthly average for each year of data and by province [see Additional files 2, 3, 4 and 5]. 
Table 1 Number of observations, mean and ranges for rainfall, ANC4, and Institutional delivery, by province (2012-2015, 2017-2019)

\begin{tabular}{|c|c|c|c|c|c|c|c|c|c|}
\hline & \multicolumn{3}{|c|}{ Rainfall (mm) } & \multicolumn{3}{|c|}{ ANC4 } & \multicolumn{3}{|c|}{ Institutional Deliveries } \\
\hline & $\bar{n}$ & Mean & Min-Max & $\mathrm{n}$ & Mean & Min-Max & $\mathrm{n}$ & Mean & Min-Max \\
\hline Cabo-Delgado & 86 & 85 & $3-385$ & 73 & 6774 & $1659-11,578$ & 73 & 5929 & $4287-8461$ \\
\hline Gaza & 86 & 50 & $8-345$ & 73 & 5030 & $3043-6023$ & 73 & 4086 & $1948-6391$ \\
\hline Inhambane & 86 & 65 & $9-352$ & 73 & 4916 & $3138-6103$ & 73 & 4043 & $2709-5469$ \\
\hline Manica & 86 & 75 & $9-463$ & 72 & 7721 & $4668-12,174$ & 73 & 6003 & $3993-8467$ \\
\hline Maputo-Cidade & NA & NA & NA & 73 & 3152 & $0-5043$ & 73 & 3464 & $2296-5820$ \\
\hline Maputo-Province & 86 & 54 & $7-213$ & 73 & 3821 & $2060-5583$ & 72 & 3096 & $1957-5238$ \\
\hline Nampula & 87 & 86 & $5-376$ & 73 & 21,989 & $8762-39,298$ & 73 & 16,530 & $9072-23,601$ \\
\hline Niassa & 86 & 85 & $3-327$ & 73 & 5916 & $2123-10,158$ & 73 & 5878 & $3970-8283$ \\
\hline Sofala & 86 & 84 & $9-539$ & 73 & 7839 & $4036-12,188$ & 73 & 6635 & $4713-8858$ \\
\hline Tete & 86 & 69 & $2-360$ & 73 & 8322 & $2912-14,128$ & 73 & 6887 & $4358-9589$ \\
\hline Zambezia & 86 & 108 & $12-411$ & 73 & 17,563 & $6861-33,929$ & 73 & 12,994 & $8507-17,521$ \\
\hline
\end{tabular}

Abbreviations: $n$ number of observations; NA Not applicable

\section{Negative binomial model analysis}

Table 2 shows the results of the negative binomial model for the frequency of antenatal care utilization and institutional delivery in Mozambique. The rate of ANC4 is reduced by $1 \%$ for the rainy season compared to the dry season, adjusting for time and province (IRR $=0.99,95 \%$ CI: 0.96-1.03). While not statistically significant, we still found a decrease in ANC4 during the rainy season.

For institutional deliveries, the rate of institutional deliveries is $6 \%$ lower during the rainy season than the dry season, after adjusting for time and province (IRR $=0.94$, 95\% CI: 0.92-0.96). This shows that the rainy season has a statistically significant lower rate of institutional deliveries compared to the dry season in Mozambique.
When analyzing institutional deliveries provincially, all provinces except for Maputo-Cidade, Maputo-Province, Nampula, and Niassa have a statistically significantly lower incident rate of institutional deliveries in the rainy season (Fig. 2, left). In contrast, provincially, there is no statistically significant difference between the rainy season and the dry season for ANC visits (Fig. 2, right).

\section{Quantifying the reduction in service delivery and excess mortality}

The predicted number of institutional deliveries in Mozambique in the original rainy/dry season categorization scenario and in the always dry season scenario are presented

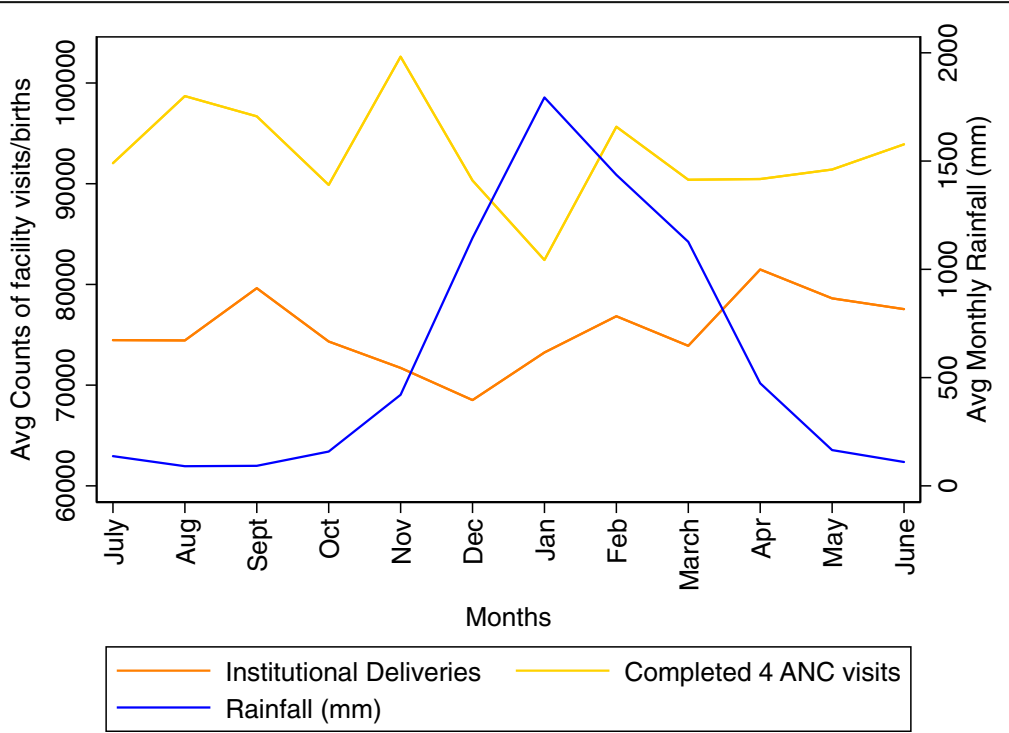

Fig. 1 National pattern of ANC visits and Institutional Deliveries against precipitation data $(2012-2015,2017-2019)$ 
Table 2 Negative Binomial Regression Analysis Results for ANC4 and institutional delivery

\begin{tabular}{|c|c|c|c|c|c|c|}
\hline \multirow[b]{2}{*}{ Variable } & \multicolumn{3}{|c|}{ ANC4 } & \multicolumn{3}{|c|}{ Institutional delivery } \\
\hline & IRR & $95 \% \mathrm{Cl}$ & $P$ value & $\overline{\text { IRR }}$ & $95 \% \mathrm{Cl}$ & $P$ value \\
\hline Rainy Season & 0.99 & $0.96-1.03$ & 0.606 & 0.94 & $0.92-0.96$ & $<0.001$ \\
\hline SISMA & 0.41 & $0.38-0.45$ & $<0.001$ & 1.06 & $1.01-1.11$ & 0.024 \\
\hline \multicolumn{7}{|l|}{ Province } \\
\hline Nampula (reference) & 1.00 & & & 1.00 & & \\
\hline Cabo-Delgado & 0.29 & $0.27-0.31$ & $<0.001$ & 0.36 & $0.34-0.37$ & $<0.001$ \\
\hline Gaza & 0.26 & $0.24-0.28$ & $<0.001$ & 0.24 & $0.23-0.26$ & $<0.001$ \\
\hline Inhambane & 0.24 & $0.22-0.26$ & $<0.001$ & 0.24 & $0.23-0.25$ & $<0.001$ \\
\hline Manica & 0.37 & $0.34-0.40$ & $<0.001$ & 0.36 & $0.34-0.38$ & $<0.001$ \\
\hline Maputo-Cidade & 0.15 & $0.14-0.16$ & $<0.001$ & 0.22 & $0.21-0.23$ & $<0.001$ \\
\hline Maputo-Province & 0.18 & $0.17-0.20$ & $<0.001$ & 0.19 & $0.18-0.20$ & $<0.001$ \\
\hline Niassa & 0.26 & $0.24-0.28$ & $<0.001$ & 0.36 & $0.34-0.37$ & $<0.001$ \\
\hline Sofala & 0.36 & $0.33-0.39$ & $<0.001$ & 0.40 & $0.39-0.42$ & $<0.001$ \\
\hline Tete & 0.38 & $0.35-0.41$ & $<0.001$ & 0.41 & $0.39-0.43$ & $<0.001$ \\
\hline Zambezia & 0.78 & $0.72-0.84$ & $<0.001$ & 0.78 & $0.75-0.82$ & $<0.001$ \\
\hline Time & 1.01 & $1.00-1.01$ & $<0.001$ & 1.00 & $1.00-1.01$ & $<0.001$ \\
\hline
\end{tabular}

Abbreviations: IRR Incident Rate Ratio; CI Confidence Interval

in Table 3. From our model, we can say that in 2021, approximately 26,546 women in Mozambique who would otherwise deliver in a facility will not do so during the rainy season. Figure 3 shows the predicted values superimposed onto the monthly count data of institutional delivery utilization at the national level.
Due to the rainy season in our model, we estimate that there would be 74 additional maternal deaths and 726 deaths of children under the age of 1 month (i.e. those most likely to be affected by institutional delivery outcomes) who would not otherwise die if the mother were able to deliver at a health facility from July 2020 to June 2021 (Table 4).

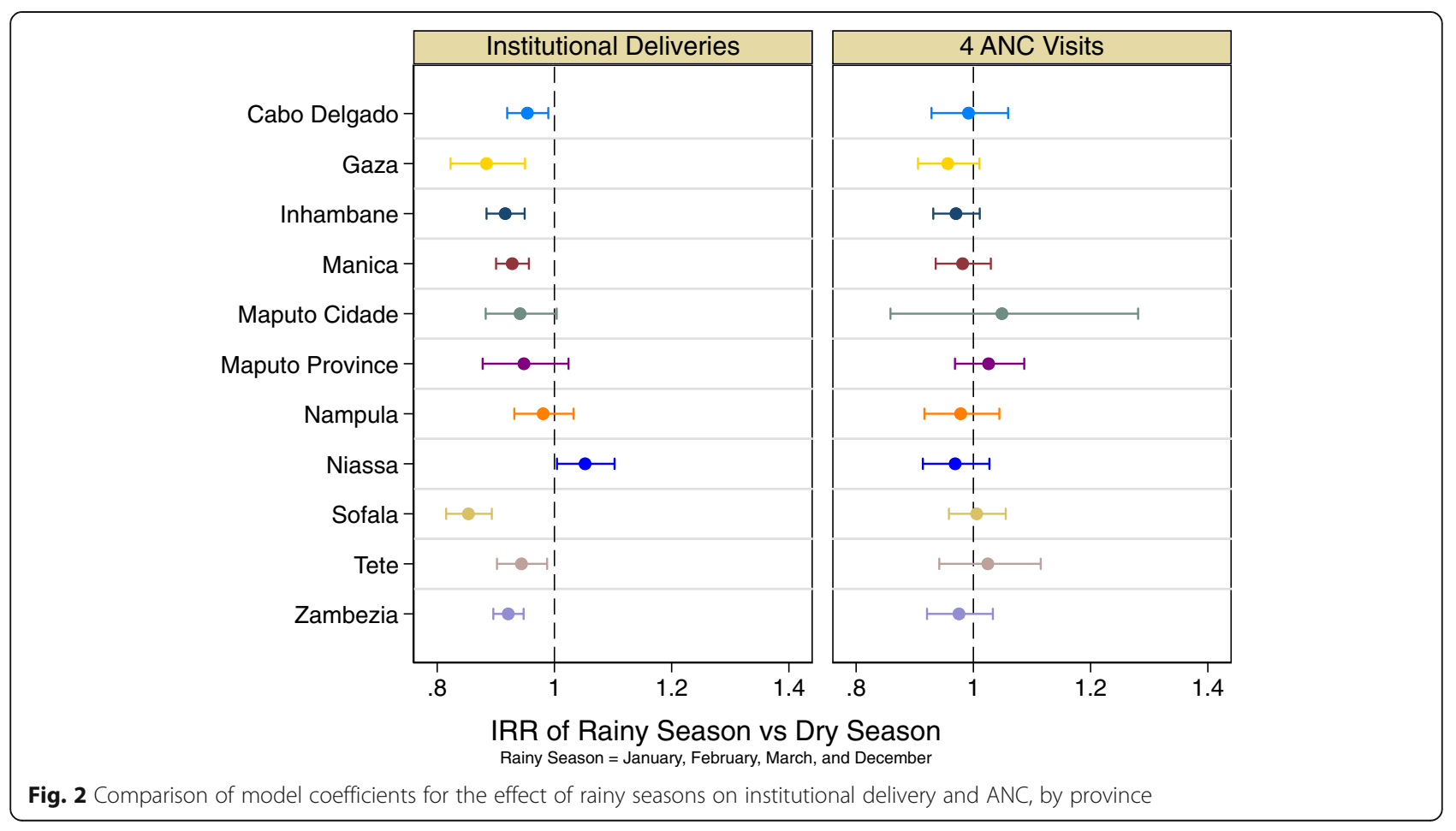


Table 3 Predicted counts of institutional deliveries and difference due to the rainy season

\begin{tabular}{lllll}
\hline Year $^{\mathbf{a}}$ & Observed Count & $\begin{array}{l}\text { Predicted count } \\
\text { using model } \\
\mathbf{n}(\mathbf{9 5 \%} \text { Cl) }\end{array}$ & $\begin{array}{l}\text { Predicted count using model } \\
\text { if all months were non-rainy } \\
\mathbf{n}(\mathbf{9 5 \%} \text { Cl) }\end{array}$ & Difference due to rainy season \\
\hline 2013 & 755,837 & $762,995(686,978-839,013)$ & $779,040(701,620-856,461)$ & 16,045 \\
2014 & 804,546 & $806,924(726,530-887,318)$ & $823,892(742,014-905,770)$ & 16,968 \\
2015 & 793,959 & $798,851(715,452-882,251)$ & $813,170(728,260-898,080)$ & 14,319 \\
2016 & - & $902,514(812,596-992,431)$ & $921,492(829,915-1,013,069)$ & 18,979 \\
2017 & $1,014,220$ & $1,009,141(908,600-1,109,682)$ & $1,030,362(927,965-1,132,758)$ & 21,221 \\
2018 & $1,091,631$ & $1,067,241(960,911-1,173,570)$ & $1,089,683(981,391-1,197,975)$ & 22,442 \\
2019 & - & $1,128,686(1,016,234-1,241,137)$ & $1,152,420(1,037,893-1,266,947)$ & 23,734 \\
2020 & - & $1,193,668(1,074,742-1,312,594)$ & $1,218,769(1,097,649-1,339,890)$ & 25,101 \\
2021 & - & $1,262,392(1,136,619-1,388,164)$ & $1,288,938(1,160,844-1,417,032)$ & 26,546 \\
\hline
\end{tabular}

${ }^{a}$ Observed counts not included for years we do not have data for all 12 months

\section{Discussion}

Our findings indicate that in Mozambique (1) season is significantly associated with institutional deliveries, whose counts are lower during the rainy season and that (2) while there is a decrease in counts for ANC4 during the rainy season, it is not statistically significant in most provinces.

These findings make sense given the nature of these two health interventions. While ANC visits should occur within given time periods (i.e. its recommended for the first contact to be at any time within the first trimester), there is no requirement for them to happen on a specific day. Therefore, if a woman intended to go to her ANC visit on a given day but the roads are inaccessible due to heavy rainfall, she can easily postpone her trip for another day when the rain has stopped and the roads are in better condition. She would still be within the recommended visit period window and therefore compliant with her ANC schedule. However, women have little say in when their labour starts, and correspondingly have no say in road or weather conditions on that day.

The link between high ANC4 rates and high institutional delivery attendance has been documented [2528]. Given this, our findings suggest that the significant decrease in institutional delivery is likely not due to women choosing not to deliver in health facilities, but rather, not being physically capable of reaching the health facility in time. The implications of these findings are therefore two-fold: (1) that Mozambique has generated some interest for pregnant women to utilize maternal health services, and (2) that gains in maternal health

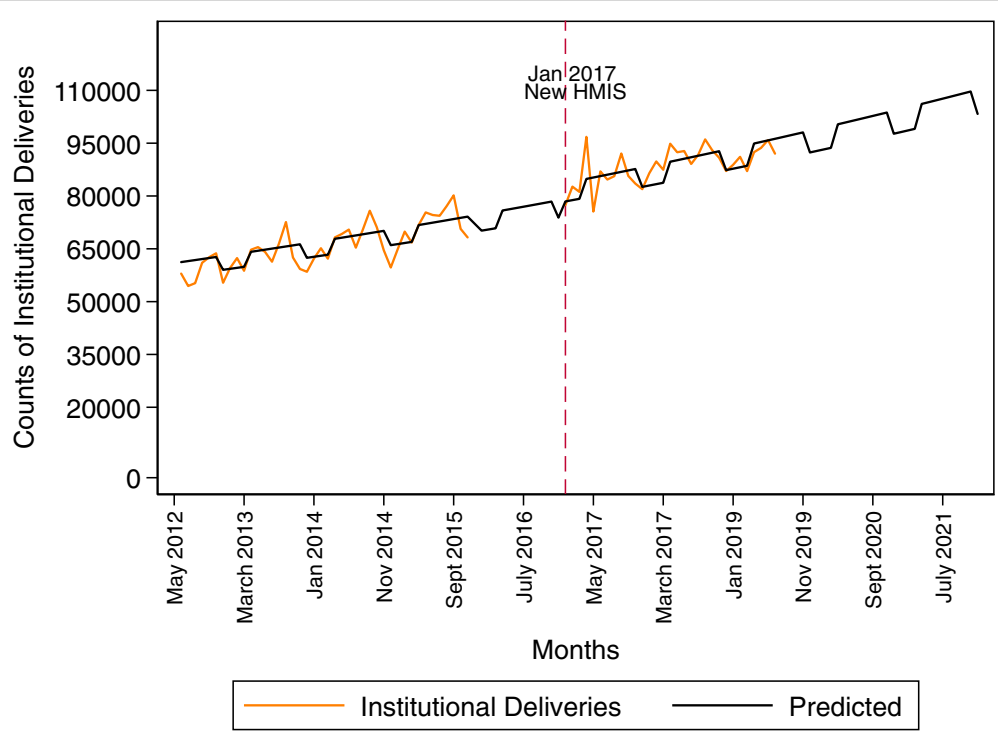

Fig. 3 Predictive model (June 2012 - December 2019) 
Table 4 Number of maternal and child deaths before and after decrease of institutional delivery utilization

\begin{tabular}{lllll}
\hline & Assuming no effect of rainy season & With effect of rainy season & Difference & Percent increase \\
\hline Number of maternal deaths & 3297 & 3371 & 74 & $2.24 \%$ \\
Number of $<$ 1 month deaths & 31,704 & 32,430 & 726 & $2.29 \%$
\end{tabular}

are being missed, not because of the health sector but because of lack of investments in infrastructure and transportation options for pregnant women.

The governmental initiatives and strategic plans to improve maternal health indicate support from the government and desire to address obstacles to maternal health services [19]. Indeed, while women's health (including maternal health) is being prioritized, gains in women's health have been modest due to in part to poor implementation of government policies [29].

One solution to address the issue of access to maternal health services is to bring the services to the people who need them, either by using mobile clinics or by leveraging community health workers in remote areas. Mobile clinics are currently used in Mozambique to deliver primary health and maternal and child health services, along with HIV and TB services [30]. Community health workers are also responsible for providing pre-natal counseling and referrals to health facilities, but they do not provide ANC services themselves [31]. However, these options alone cannot close the gap. Firstly, the quality of maternal and child health services - particularly ANC4 - can vary significantly since it measures interaction with a skilled provider, but does not always speak to what service was received. Indeed, an analysis of 46 LMICs found that community-based ANC services had the lowest score for delivering all four ANC interventions [32]. Additionally, mobile clinics are often overwhelmed by demand, leading to rapid stock-outs of medication and patients not being able to be seen by a health care provider, which causes frustration and discourages returning [33].

Importantly, the mobile clinic approach is not suitable for institutional deliveries which by definition require access to a health facility. Studies in other settings have found that time to travel to delivery site [34] and availability of a clinic in the community [35] are associated with higher rates of institutional delivery. Maternity waiting homes are part of the national plan for health, but these too are imperfect solutions. Maternity waiting homes, if utilized, do have potential for improving maternal health outcomes. However, direct (e.g., transportation costs, food, lodging fees) and indirect (e.g., lost wages while at the waiting home, no available caretaker for other children) costs have been found to be significant barriers to the utilization of maternity waiting homes by a systematic review [36].
At a more upstream level, mother's education is also associated with increased utilization of maternal health services [37], and access to education is also determined by roads and access to transport. Indeed, a 2015 study in rural Mozambique found lack of school and lack of access to health care services were most commonly cited as the biggest barrier to individuals' and their families' health [13].

Solutions to address problems related to access to health care must involve sectors outside the health sector. Gains on the health front are at risk of being lost unless infrastructure and transportations issues are addressed taking into account the meteorological realities of rural Mozambique. Every year, we estimate that 3297 mothers die due to reasons related to their pregnancy or childbirth. According to our analysis, around $2 \%$ of those deaths are related to the mere fact that mothers do not travel to a health facility because of the rain. While this is a small percentage, it shows how marginal factors relating to health system accessibility can have real-world, life-or-death consequences. A rural resident of Zambezia province described the problem succinctly: "Access to health care is a big problem. I left my home this morning to reach here. We have a small clinic, but they don't do blood tests. Sometimes we have transport, but today because of the rain it was difficult. It takes about 3 hours to walk, more if you are sick." [13].

Although our analysis estimated the number of maternal and child death that would not otherwise occur if the women delivered in the health facility but did not due to the rainy season, it is important to consider that there are other reasons why women do not deliver in health facilities. These may include maternal age, religion, parity, and exposure to information [38, 39].

\section{Limitations}

Considering that only some facility-based data was available, a limitation is that we do not have demographic data on the women that are visiting the health facilities each month, such as their age, income level, or number of children, and we cannot account for potential interor intra-personal barriers to access to health services. Our analysis could have been strengthened if we had access to additional information about these women, such as distance from their residence to the health facility, to determine if they live in a rural region with limited road access, or far from the health facility. The generalization 
of the conclusions to all pregnant women in Mozambique is therefore limited. Peaks of health facility use in certain months that seem inconsistent with the overall trend could also be due to fertility patterns, occupational migration trends, or other patterns not captured in our data.

We also note that our conclusions are drawn from analyzing routine data. Routine data quality has been called into question with regards to completeness, timeliness, representativeness and accuracy. However, others have used routine data in Mozambique and argue that data in Mozambique's HMIS platform was of sufficient quality to evaluate some health programs [40, 41], with one study reporting high availability and reliability of institutional delivery in particular. Of note, both studies refer to the pre-2016 Modulo Basico platform. We therefore caution that the interpretation of our results depends on the quality of the data contained in Mozambique's HMIS platform.

There are other ways in which one can approach geo-spatial analysis. Several other groups have developed more sophisticated methods that involve geographical information system (GIS)-based spatial analysis, spatio-temporal modelling, or a combination of survey data and spatial analysis [15, 42, 43]. Others have considered uncertainty by incorporating spatial autocorrelation along with area overlap [44]. These types of analyses require specific types of data and complex methods. Since we were working with HMIS data and limited geographic data, we decided to limit the scope of our methods to a regression analysis of count data.

\section{Conclusion}

In Mozambique, fewer women deliver at a health facility during the rainy season than during the dry season, meaning that fewer women have access to lifesaving obstetric services when they need it. Until the role of infrastructure, specifically roads, is given consideration as a health systems priority, these geographical inequities will persist. This study highlights the need to address barriers to receiving care during pregnancy or childbirth. Due attention should be given to reducing geographic inequities, particularly in rural regions with a less developed road network. Doing so may require intersectoral collaboration, such as between the Ministry of Health and Ministry of Public Works and Housing - the department responsible for building and managing roads. While more research is needed to evaluate the impact of increasing extreme weather and heavy rainfall events on accessing health services, these results can help inform service delivery and infrastructure development programs.

\section{Supplementary information}

Supplementary information accompanies this paper at https://doi.org/10. 1186/s12913-020-05807-0.

Additional file 1. Precipitation Data, Nationally. Average monthly rainfall by year (PDF $65 \mathrm{~KB}$ )

Additional file 2. Institutional Deliveries by Month 2012-2019, Nationally. National monthly average of institutional deliveries for each year of data (PDF $60 \mathrm{~KB}$ )

Additional file 3. Completed ANC4 Visits by Month 2012-2019, Nationally. National monthly average of 4 completed ANC visits for each year of data (PDF 59 KB)

Additional file 4. Institutional Delivery Trends by Province (2012-2019). Average monthly rainfall and institutional deliveries by province (PDF $44 \mathrm{~KB}$ )

Additional file 5. ANC Trends by Province (2012-2019). Average monthly rainfall and 4 completed ANC visits by province (PDF 44 KB)

\section{Abbreviations}

AIC: Akaike information criterion; ANC: Antenatal care; CHIRPS: Climate hazards group infrared precipitation with stations; Cl: Confidence Interval; DHS: Demographic and health survey; HIV: Human immunodeficiency viruses; HMIS: Health management information system; IRR: Incident rate ratio; LiST: Lives saved tool; NA: Not applicable; PESS: Plano estratégico do sector da saúde; SIS-MA: Sistema de informação para a saúde-monitoria e avaliação; TB: Tuberculosis; TBA: Traditional birth attendant; USAID: United States Agency for International Development; VIF: Variance inflation factors

\section{Acknowledgements}

Not Applicable.

\section{Authors' contributions}

TR, BDS, and TSL designed the analysis. JSA obtained the data for analysis. BDS performed the data cleaning and analysis. BDS and TSL wrote the manuscript. JSA and TR provided comments and feedback. All authors have reviewed and approve the final version of the manuscript.

\section{Funding}

This study was carried out as part of the National Evaluation Platform project funded by Global Affairs Canada (project number CA-3-M013604001). The funders had no role in study design, data collection and analysis, decision to publish, or preparation of the manuscript.

\section{Availability of data and materials}

The data that support the findings of this study are available from Mozambique's Departamento de Planificação e Cooperação (DPC) but restrictions apply to the availability of these data, which were used under license for the current study, and so are not publicly available. Data are however available from the authors upon reasonable request and with permission of the DPC.

Ethics approval and consent to participate

Not applicable.

\section{Consent for publication}

Not applicable.

\section{Competing interests}

The authors declare no competing interests.

\section{Author details}

1Johns Hopkins Bloomberg School of Public Health, Baltimore, MD, USA. ${ }^{2}$ Instituto Nacional de Saúde, Ministério da Saúde, Maputo, Mozambique.

Received: 17 July 2020 Accepted: 7 October 2020

Published online: 15 October 2020

References

1. Ferrão $\mathrm{J}$, Mendes $J \mathrm{M}$, Painho M. Modelling the influence of climate on malaria occurrence in Chimoio Municipality, Mozambique. Parasit Vectors 
[Internet]. 2017 Dec 25 [cited 2020 Apr 3];10(1):260. Available from: http:// parasitesandvectors.biomedcentral.com/articles/10.1186/s13071-017-2205-6.

2. Horn LM, Hajat A, Sheppard L, Quinn C, Colborn J, Zermoglio MF, et al. Association between precipitation and diarrheal disease in Mozambique. Int J Environ Res Public Health. 2018;15:4.

3. Nguyen M, Howes RE, Lucas TCD, Battle KE, Cameron E, Gibson HS, et al. Mapping malaria seasonality in Madagascar using health facility data. BMC Med. 2020;18:1.

4. Blanford Jl, Kumar S, Luo W, MacEachren AM. It's a long, long walk: accessibility to hospitals, maternity and integrated health centers in Niger. Int J Health Geogr. 2012;11:24.

5. Gabrysch S, Cousens S, Cox J, Campbell OMR. The influence of distance and level of care on delivery place in rural Zambia: A study of linked national data in a geographic information system. PLoS Med. 2011;8:1.

6. Schoeps A, Gabrysch S, Niamba L, Sié A, Becher H. Effect of Distance to Health-Care Facilities on Childhood Mortality in Rural Burkina Faso. Am J Epidemiol [Internet]. 2011 Mar 1 [cited 2020 Apr 3];173(5):492-8. Available from: https://academic.oup.com/aje/article/173/5/492/89038.

7. Treacy L, Bolkan HA, Sagbakken M. Distance, accessibility and costs. Decision-making during childbirth in rural Sierra Leone: A qualitative study. Räisänen SH, editor. PLoS One [Internet]. 2018 Feb 20 [cited 2020 Apr 3]; 13(2):e0188280. Available from: http://dx.plos.org/10.1371/journal.pone.01 88280.

8. Dos Anjos LA, Cabral P. Geographic accessibility to primary healthcare centers in Mozambique. Int J Equity Health [Internet]. 2016;15(1):1-13 Available from: http://equityhealthj.biomedcentral.com/articles/10.1186/s12 939-016-0455-0.

9. Biza A, Jille-Traas I, Colomar M, Belizan M, Requejo Harris J, Crahay B, et al. Challenges and opportunities for implementing evidence-based antenatal care in Mozambique: a qualitative study. BMC Pregnancy Childbirth. 2015; 15(1):200. Available from. https://doi.org/10.1186/s12884-015-0625-x.

10. (MISAU) M da $\mathrm{S}$, (INE) IN de E, (ICFI). ICFI. Moçambique Inquérito Demográfico e de Saúde. Calverton, Maryland, USA; 2011.

11. Anselmi L, Lagarde M, Hanson K. Health service availability and health seeking behaviour in resource poor settings: evidence from Mozambique. Health Econ Rev. 2015:5(1):26. Available from. https://doi.org/10.1186/ s13561-015-0062-6.

12. Munguambe K, Boene $H$, Vidler M, Bique C, Sawchuck D, Firoz T, et al. Barriers and facilitators to health care seeking behaviours in pregnancy in rural communities of southern Mozambique. Reprod Health [Internet]. 2016 Jun 8 [cited 2020 Apr 4];13(1):31. Available from: http://reproductive-healthjournal.biomedcentral.com/articles/10.1186/s12978-016-0141-0.

13. Schwitters A, Lederer P, Zilversmit L, Gudo PS, Ramiro I, Cumba L, et al. Barriers to health care in rural Mozambique: a rapid ethnographic assessment of planned mobile health clinics for ART. Glob Heal Sci Pract. 2015;3(1):109-16.

14. Transport \& ICT. Measuring Rural Access: Using new technologies [Internet]. Washington DC; 2016 [cited 2020 Mar 30]. Available from: http://documents. worldbank.org/curated/en/367391472117815229/pdf/107996-REVISEDPUBLIC-MeasuringRuralAccessweb.pdf.

15. Makanga PT, Schuurman N, Sacoor C, Boene HE, Vilanculo F, Vidler M, et al. Seasonal variation in geographical access to maternal health services in regions of southern Mozambique. Int J Health Geogr. 2017:16:1.

16. United Nations Department of Economic and Social Affairs. The Millennium Development Goals Report 2015. 2016.

17. Alkema L, Chou D, Hogan D, Zhang S, Moller AB, Gemmill A, et al. Global, regional, and national levels and trends in maternal mortality between 1990 and 2015, with scenario-based projections to 2030: a systematic analysis by the un maternal mortality estimation inter-agency group. Lancet. 2016 Jan 30;387(10017):462-74.

18. United Nations Population Division D of E and SA. World Population Prospects - Population Division - United Nations [Internet]. World Population Prospects: The 2017 Revision. 2017. Available from: https:// population.un.org/wpp/DataQuery/.

19. Ministério de Saúde (MISAU). Plano Estratégico do Sector de Saúde. 20142019:2014

20. Agadjanian V, Yao J, Hayford SR. Place, time and experience: barriers to universalization of institutional child delivery in rural Mozambique. Int Perspect Sex Reprod Health. 2016;42(1):21-31.

21. USAID. Mozambique: Malaria Operational Plan FY 2018
22. Funk CC, Peterson PJ, Landsfeld MF, Pedreros DH, Verdin JP, Rowland JD, et al. A quasi-global precipitation time series for drought monitoring: U.S. Geological Survey Data Series 832. Usgs [Internet]. 2014 [cited 2020 Apr 3];4. Available from: https://pubs.usgs.gov/ds/832/pdf/ds832.pdf\%0Ahttps://pubs. er.usgs.gov/publication/ds832.

23. StataCorp. Stata Statistical Software: Release 15. College Station: StataCorp LLC; 2017.

24. Walker N, Tam Y, Friberg IK. Overview of the lives saved tool (LiST). BMC Public Health. 2013;13(3):S1. Available from. https://doi.org/10.1186/14712458-13-S3-S1.

25. Abebe E, Seid A, Gedefaw G, Haile ZT, Ice G. Association between antenatal care follow-up and institutional delivery service utilization: analysis of 2016 Ethiopia demographic and health survey. [cited 2020 Apr 30]; Available from: https://doi.org/10.1186/s12889-019-7854-2.

26. Assefa M, Fite RO, Taye A, Belachew T. Institutional delivery service use and associated factors among women who delivered during the last 2 years in Dallocha town, SNNPR, Ethiopia. Nurs Open [Internet]. 2020 Jan 1 [cited 2020 Apr 30];7(1):186-94. Available from: https://onlinelibrary.wiley.com/doi/ abs/10.1002/nop2.378.

27. Hagos S, Shaweno D, Assegid M, Mekonnen A, Afework MF, Ahmed S. Utilization of institutional delivery service at Wukro and Butajera districts in the Northern and South Central Ethiopia. BMC Pregnancy Childbirth [Internet]. 2014 May 28 [cited 2020 Apr 30];14(1):178. Available from: http:// bmcpregnancychildbirth.biomedcentral.com/articles/10.1186/1471-2393-14-1 78.

28. Mageda K, Mmbaga EJ. Prevalence and predictors of institutional delivery among pregnant mothers in Biharamulo district, Tanzania: A cross-sectional study. Pan Afr Med J. 2015:26:21.

29. Qiu M, Sawadogo-Lewis T, Ngale K, Cane RM, Magaço A, Roberton T. Obstacles to advancing women's health in Mozambique: a qualitative investigation into the perspectives of policy makers. Glob Heal Res Policy [Internet]. 2019 Dec 24 [cited 2020 May 25];4(1):28. Available from: https:// ghrp.biomedcentral.com/articles/10.1186/s41256-019-0119-x.

30. Mozambique Ministry of Health (MISAU), Centers for Disease Control [Mozambique]. Mobile Health Clinic Plan. Maputo, Mozambique; 2012.

31. Ministério da Saúde (MISAU). Programa de revitalização dos agentes polivalentes elementares. Maputo, Mocambique; 2010.

32. Powell-Jackson T, Macleod D, Benova L, Lynch C, OMR C. The role of the private sector in the provision of antenatal care: a study of Demographic and Health Surveys from 46 low- and middle-income countries. Trop Med Int Heal [Internet]. 2015;20(2):230-9. [cited 2020 May 25] Available from: https://doi.org/10.1111/tmi.12414.

33. Saad-Haddad G, Dejong J, Terreri N, Restrepo-Méndez C, Perin J, Vaz L, et al. Patterns and determinants of antenatal care utilization: analysis of national survey data in seven countdown countries . J Glob Health [Internet]. 2016 Jun [cited 2020 May 25];6(1). Available from: www.jogh.org.

34. Glei DA, Goldman N. Ethnicity \& Health Understanding Ethnic Variation in Pregnancy-related Care in Rural Guatemala. 2010 [cited 2020 Jun 1]; Available from: https://doi.org/10.1080/13557850050007301.

35. Falkingham J. Inequality and Changes in Women's Use of Maternal Healthcare Services in Tajikistan. Stud Fam Plann [Internet]. 2003 Mar 1 [cited 2020 May 25];34(1):32-43. Available from: http://doi.wiley.com/10.1111/j.172 8-4465.2003.00032.x

36. Van Lonkhuijzen L, Stekelenburg J, Van Roosmalen J. Maternity waiting facilities for improving maternal and neonatal outcome in low-resource countries; 2012

37. Say $L$, Raine R. A systematic review of inequalities in the use of maternal health care in developing countries: examining the scale of the problem and the importance of context Public health reviews. Bull World Health Organ [Internet]. 2007 [cited 2020 May 25];85(10). Available from: http:// www.who.

38. Boah M, Mahama AB, Ayamga EA. They receive antenatal care in health facilities, yet do not deliver there: predictors of health facility delivery by women in rural Ghana. BMC Pregnancy Childbirth. 2018;18(1):125. Available from. https://doi.org/10.1186/s12884-018-1749-6.

39. Kifle MM, Kesete HF, Gaim HT, Angosom GS, Araya MB. Health facility or home delivery? Factors influencing the choice of delivery place among mothers living in rural communities of Eritrea. J Health Popul Nutr. 2018 Oct;37(1):22. 
40. Wagenaar BH, Sherr K, Fernandes Q, Wagenaar AC. Using routine health information systems for well-designed health evaluations in low- and middle-income countries. Health Policy Plan. 2016 Feb;31 (1):129-35.

41. Gimbel S, Micek M, Lambdin B, Lara J, Karagianis M, Cuembelo F, et al. An assessment of routine primary care health information system data quality in Sofala Province, Mozambique. Popul Health Metr [Internet]. 2011 May 13; 9:12. Available from: https://pubmed.ncbi.nlm.nih.gov/21569533.

42. Yao J, Agadjanian V. Bypassing health facilities in rural Mozambique: spatial, institutional, and individual determinants. BMC Health Serv Res. 2018;18(1): 1006. Available from. https://doi.org/10.1186/s12913-018-3834-y.

43. Eide AH, Dyrstad K, Munthali A, Van Rooy G, Braathen SH, Halvorsen T, et al. Combining survey data, GIS and qualitative interviews in the analysis of health service access for persons with disabilities. BMC Int Health Hum Rights. 2018;18(1):26. Available from. https://doi.org/10.1186/s12914-018$0166-2$.

44. Zhu L, Pickle LW, Pearson JB. Confidence intervals for rate ratios between geographic units. Int J Health Geogr. 2016;15(1):44. Available from. https:// doi.org/10.1186/s12942-016-0073-5.

\section{Publisher's Note}

Springer Nature remains neutral with regard to jurisdictional claims in published maps and institutional affiliations.

- fast, convenient online submission

- thorough peer review by experienced researchers in your field

- rapid publication on acceptance

- support for research data, including large and complex data types

- gold Open Access which fosters wider collaboration and increased citations

- maximum visibility for your research: over $100 \mathrm{M}$ website views per year

At $\mathrm{BMC}$, research is always in progress.

Learn more biomedcentral.com/submissions 